\title{
Quick and efficient synthesis of Morita-Baylis-Hillman adducts of isatin derivatives
}

\author{
Kurosh Rad-Moghadam* and Leila Youseftabar-Miri \\ Department of Chemistry, Faculty of Science, University of Guilan, \\ PO Box 41335-19141, Rasht, Iran \\ E-mail: radmm@guilan.ac.ir
}

DOI: http://dx.doi.org/10.3998/ark.5550190.0012.b04

\begin{abstract}
An improvement in the rates of Morita-Baylis-Hillman reactions between isatin derivatives and acrylic esters or acrylonitrile under solvent-free conditions is presented. The reactions proceeded expediently at $0{ }^{\circ} \mathrm{C}$ under catalysis by 1,4-diazabicyclo[2,2,2]octane (DABCO) to afford the desired adducts. The optimized conditions are indicative of the presence of the more ordered transition states involved in these reactions, supporting the previously suggested mechanism for similar reactions.
\end{abstract}

Keywords: Morita-Baylis-Hillman adducts; Oxindole; Isatin; Solvent-free

\section{Introduction}

Carbon-carbon bond-forming reactions are usually essential tools for molecular architecture and also in total synthesis of organic compounds. ${ }^{1-2}$ They have been the subject of vast investigations whereupon now chemists are provided with several reactions like Diels-Alder reaction, Wittig reaction, ring-closing metathesis, Ugi reaction, Passerini reaction, Heck reaction, and recently the Morita-Baylis-Hillman reaction to create carbon-carbon bonds. ${ }^{3}$ The commonly known Morita-Baylis-Hillman reaction $(\mathrm{MBH})$ results in addition of an activated olefin (containing conjugated electron-withdrawing groups) onto an aldehyde, activated ketone or imine grouping at $\alpha$-position to afford some unique multifunctional alkenes. ${ }^{4}$ Tertiary amines are used in this reaction as nucleophilic catalysts where 1,4-diazabicyclo[2,2,2]octane (DABCO) is the most widely used catalyst. ${ }^{5}$ The $\mathrm{MBH}$ reaction has attracted much interest due to its total atom economy, wide functional group tolerance, mild reaction conditions, and the ability to generate densely functionalized alkenes of promising synthetic utility and biological activities. ${ }^{4,5}$ Despite these significant advantages, the $\mathrm{MBH}$ reactions are usually associated with slow rates. Therefore, several protocols have been proposed to improve their rates, such as use of 
microwave, ${ }^{6}$ ultrasound, ${ }^{7}$ salt and metal addition, ${ }^{8}$ high pressure ${ }^{9}$ and ionic liquids. ${ }^{10}$ According to the most accepted mechanism, as depicted in scheme 1, the reaction proceeds through a tandem addition of the tertiary amine, the electron-deficient alkene, and a carbonyl compound to give the intermediate zwitterionic species $\mathbf{1}$ and 2. ${ }^{11}$ Isatin is an active carbonyl compound, which like aldehydes can take part in $\mathrm{MBH}$ reaction. Being prompted by recent interests in the synthesis of indolin-2-ones from isatin derivatives, ${ }^{12-15}$ we planned to investigate the possible improvement of $\mathrm{MBH}$ reaction of isatin and acrylic esters or acrylonitrile for synthesis of 3hydroxy-3-vinylindolin-2-ones. The MBH adducts of isatin have found the worth of being used as precursors in organic synthesis. ${ }^{16}$ Moreover, they belong to the class of indolin-2-ones which are known to possess a variety of biological activities. ${ }^{17}$ In particular, the 3-substituted-3hydroxyindolin-2-one moiety is present in a number of bioactive alkaloids such as donwelwitindolinone $\mathrm{C}$, donaaxaridine, 3-hydroxyglucoisatine, and several active biomimetic molecules. $^{18-20}$

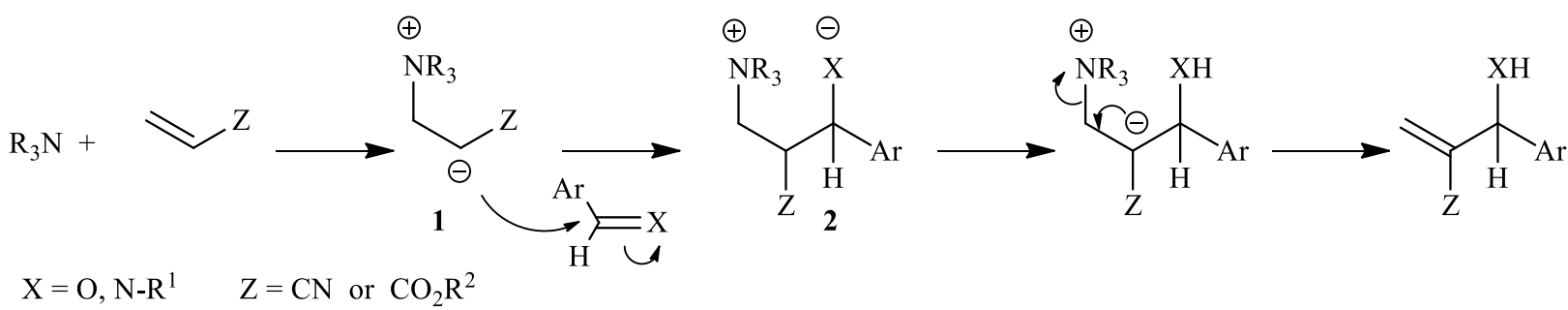

Scheme 1. A mechanism for MBH reactions.

\section{Results and Discussion}

Based on our literature survey, there are only two reports on the $\mathrm{MBH}$ reactions of isatin derivatives. ${ }^{12,13}$ Though synthetically useful, these methods suffer from low reaction rates. Thus, the development of an environmentally benign and fast method for the synthesis of MoritaBaylis-Hillman adducts of isatin derivatives is in demand. To attain this goal, we were given the results of Rafel et $a ._{.}{ }^{21}$ and de Souza et al, ${ }^{11}$ about the nature of MBH reaction of aldehydes, as a guideline to optimize the reaction parameters. Our initial trials on the model reaction involving 5-bromoisatin and ethyl acrylate using different quantities of DABCO and at variable temperatures were encouraging.

As Table 1 shows, under solvent-free condition, the reaction went to complete in a few minutes at $0{ }^{\circ} \mathrm{C}$ and proceeded efficiently with the optimum amount of $100 \mathrm{~mol} \%$ of DABCO. Two equivalents of ethyl acrylate are required to assure achieving the best yields in much reduced times under the optimum conditions (Table 1 entry 4 and 7). Table 1 also displays a deviation leading to production of uncharacterized byproducts when similar conditions were taken at higher temperatures. 
In the next phase of this investigation, the obtained optimum parameters were examined in some polar solvents, including the previously reported ones, for the model reactions between isatin and acrylonitrile (Table 2, entry 8) or 5-bromoisatin and ethyl acrylate (Table 3, entry 9).

Table 1. The MBH reaction between 5-bromoisatin and ethyl acrylate at various temperatures under solvent-free conditions

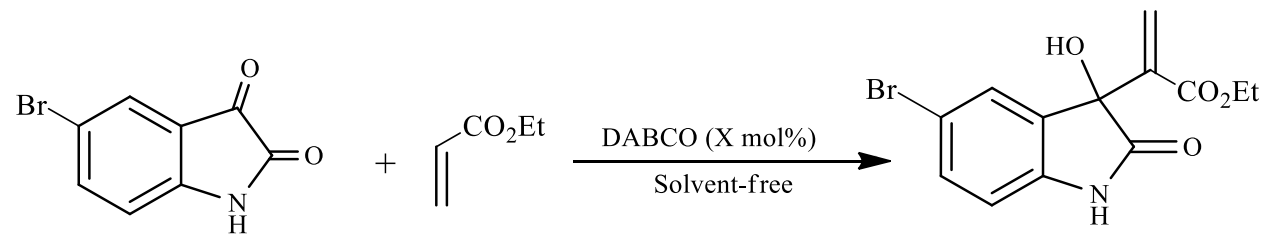

\begin{tabular}{ccccc}
\hline Entry & DABCO $(\mathrm{mol} \%)$ & Temperature $\left({ }^{\circ} \mathrm{C}\right)$ & Time & Yield $^{\mathrm{a}}(\%)$ \\
\hline 1 & 100 & 70 & $60 \mathrm{~min}$ & byproducts $^{\mathrm{b}}$ \\
2 & 100 & 50 & $60 \mathrm{~min}$ & byproducts $^{\mathrm{b}}$ \\
3 & 100 & 25 & $35 \mathrm{~min}$ & 78 \\
4 & 100 & 0 & $35 \mathrm{~min}$ & 83 \\
5 & 100 & -5 & $40 \mathrm{~min}$ & 83 \\
6 & 50 & 0 & $60 \mathrm{~min}$ & 37 \\
7 & 100 & -5 & $90 \mathrm{~min}$ & $46^{\mathrm{c}}$ \\
\hline
\end{tabular}

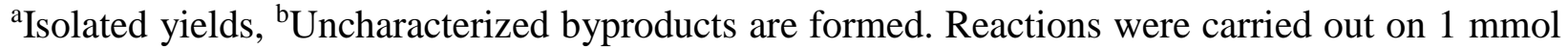
scale, with molar ratio of isatin $(1 \mathrm{mmol})$ : ethyl acrylate $(2 \mathrm{mmol}) .{ }^{\mathrm{c}}$ The reaction was carried out on $1 \mathrm{mmol}$ scale, with molar ratio of 5-bromoisatin $(1 \mathrm{mmol})$ : ethyl acrylate $(1 \mathrm{mmol})$.

Table 2. Reaction between isatin and acrylonitrile catalyzed by $\mathrm{DABCO}(\mathrm{X}$ mol \%) in polar solvents

\begin{tabular}{cccccc}
\hline Entry & Solvent & $\begin{array}{c}\text { DABCO }(\mathrm{mol} \\
\%)\end{array}$ & $\begin{array}{c}\text { Temperature } \\
\left({ }^{\circ} \mathrm{C}\right)\end{array}$ & Time & Yield $^{\mathrm{a}}(\%)$ \\
\hline 1 & $\mathrm{MeOH}$ & 100 & 0 & $60 \mathrm{~min}$ & 56 \\
2 & $\mathrm{MeOH}$ & 100 & 25 & $60 \mathrm{~min}$ & 53 \\
3 & $\mathrm{MeOH}$ & 100 & 70 & $60 \mathrm{~min}$ & byproducts $^{\mathrm{b}}$ \\
5 & $\mathrm{THF}$ & 15 & 0 & $120 \mathrm{~min}$ & 25 \\
6 & $\mathrm{THF}$ & 100 & 25 & $30 \mathrm{~min}$ & $68^{\mathrm{c}}$ \\
7 & $\mathrm{THF}$ & 100 & 0 & $30 \mathrm{~min}$ & $70^{\mathrm{c}}$ \\
8 & $\mathrm{THF}$ & $15^{\mathrm{d}}$ & 25 & 4 days & $69^{\mathrm{d}}$ \\
\hline
\end{tabular}

asolated yields based on isatin, the products were separated by column chromatography on silica

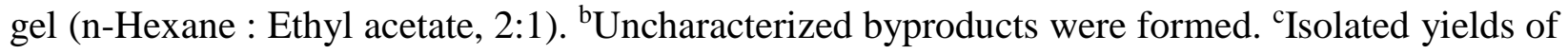
the pure product obtained after crystallization of the crude solid from $\mathrm{EtOH}(95.5 \%)$. ${ }^{\mathrm{d}}$ Reference 13. Reactions were carried out on $1 \mathrm{mmol}$ scale in $2 \mathrm{~mL}$ of solvent, molar ratio of isatin (1 mmol): acrylonitrile (2 mmol). 
All the experiments were carried out in comparable times (up to $2 \mathrm{~h}$ ) in solution phases, but the reactions were slower than those carried out under solvent-free conditions. As shown in Table 2 and Table 3, the effect of low temperature is somewhat latent in solution phase. Noteworthy, the highest reaction rates can be obtained by using $100 \mathrm{~mol} \%$ of DABCO, meanwhile a deviation in the course of reaction favoring the formation of byproducts again occurs at higher temperatures.

Table 3. Reaction between 5-bromoisatin and ethyl acrylate under catalysis of DABCO (X mol $\%$ ) in polar solvents

\begin{tabular}{|c|c|c|c|c|c|}
\hline Entry & Solvent & DABCO $(\mathrm{mol} \%)$ & Temp. $\left({ }^{\circ} \mathrm{C}\right)$ & Time & Yield $^{\mathrm{a}}(\%)$ \\
\hline 1 & $\mathrm{MeOH}$ & 100 & 25 & $2 \mathrm{~h}$ & 43 \\
\hline 2 & $\mathrm{MeOH}$ & 100 & 0 & $2 \mathrm{~h}$ & 45 \\
\hline 3 & $\mathrm{EtOH}$ & 100 & 25 & $2 \mathrm{~h}$ & 25 \\
\hline 4 & $\mathrm{EtOH}$ & 100 & 0 & $2 \mathrm{~h}$ & 30 \\
\hline 5 & Water & 100 & 25 & $2 \mathrm{~h}$ & 20 \\
\hline 6 & Water & 100 & 0 & $2 \mathrm{~h}$ & 20 \\
\hline 7 & $\mathrm{i}-\mathrm{PrOH}$ & 100 & 25 & $2 \mathrm{~h}$ & 30 \\
\hline 8 & i-PrOH & 100 & 0 & $2 \mathrm{~h}$ & 35 \\
\hline 9 & $\begin{array}{c}\mathrm{THF} / \mathrm{EtOH} \\
(1: 1)^{\mathrm{b}}\end{array}$ & 15 & 25 & 11days & $95^{b}$ \\
\hline 10 & $\begin{array}{c}\mathrm{THF} / \mathrm{EtOH} \\
(1: 1)\end{array}$ & 100 & 25 & $2 \mathrm{~h}$ & 52 \\
\hline 11 & $\begin{array}{c}\mathrm{THF} / \mathrm{EtOH} \\
(1: 1)\end{array}$ & 100 & 0 & $2 \mathrm{~h}$ & 62 \\
\hline
\end{tabular}

${ }^{a}$ Isolated yields based on 5-bromoisatin. ${ }^{b}$ Reference 12. Reactions were carried out on $1 \mathrm{mmol}$ scale in $2 \mathrm{~mL}$ of solvent, using molar ratio of 5-bromoisatin ( $1 \mathrm{mmol})$ : ): ethyl acrylate $(2 \mathrm{mmol})$.

According to the above results we chose $100 \mathrm{~mol} \%$ of DABCO in solvent-free conditions and set out to examine the generality of the method by using other derivatives of isatin. Results of these experiments are summarized in Table 4.

As this Table shows, compounds $\mathbf{5 b}$ and $\mathbf{5 d}$ are formed quickly, in comparison with the methods previously reported on these reactions performed in solution phases at room temperature. Noteworthy, the reactions with acrylonitrile also experienced increased rates at 0 ${ }^{\circ} \mathrm{C}$, to afford $\mathbf{5 a}$ and $\mathbf{5 c}$.

The greater rate of isatin relative to aldehydes in reaction with acrylonitrile can be better explained by extending the transition states of reaction to involve an aggregation consisted of isatin and the preformed zwitterionic adduct 1. Such aggregations presumably are formed by stacking of the two components in which the opposite charges are less separated and set up a stabilizing electrostatic attraction with the dipole of isatin. This aggregation have a proper 
arrangement that facilitates the formation of the next adduct (Scheme 2) and clearly forms in expense of entropy, hence is more favored at lower temperatures.

Table 4. Reaction of isatin derivatives with electron-deficient olefins in solvent-free conditions
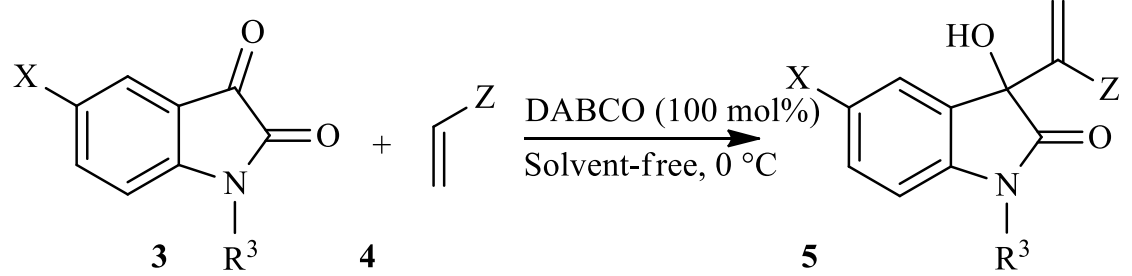

\begin{tabular}{|c|c|c|c|c|c|c|c|}
\hline \multirow{2}{*}{ Products } & \multirow{2}{*}{$\mathrm{R}^{3}$} & \multirow{2}{*}{$\mathrm{Z}$} & \multirow{2}{*}{$\mathrm{X}$} & \multirow{2}{*}{ Time (min) } & \multirow{2}{*}{ Yield $(\%)^{\mathrm{a}}$} & \multicolumn{2}{|c|}{ M.p. $\left({ }^{\circ} \mathrm{C}\right)$} \\
\hline & & & & & & Found & Reported $^{\text {b }}$ \\
\hline $5 \mathbf{a}$ & $\mathrm{CH}_{3}$ & $\mathrm{CN}$ & $\mathrm{H}$ & 30 & 76 & $116-118$ & $117-118$ \\
\hline $5 b^{c}$ & $\mathrm{Bn}$ & $\mathrm{CO}_{2} \mathrm{Me}$ & $\mathrm{H}$ & 30 & 64 & $193-195$ & 193-194 \\
\hline $5 c$ & $\mathrm{H}$ & $\mathrm{CN}$ & $\mathrm{H}$ & 5 & 85 & $181-183$ & $182-184$ \\
\hline $5 d$ & $\mathrm{H}$ & $\mathrm{CO}_{2} \mathrm{Et}$ & $\mathrm{Br}$ & 35 & 83 & 183-185 (dec.) & 194-196 (dec.) \\
\hline $5 e$ & $\mathrm{H}$ & $\mathrm{CO}_{2} \mathrm{Et}$ & I & 30 & 81 & 188-190 (dec.) & 196-200 (dec.) \\
\hline $5 f$ & $\mathrm{H}$ & $\mathrm{CO}_{2} \mathrm{Et}$ & $\mathrm{F}$ & 20 & 80 & $148-150$ (dec.) & ------ \\
\hline $5 g$ & $\mathrm{H}$ & $\mathrm{CO}_{2} \mathrm{Me}$ & $\mathrm{F}$ & 20 & 83 & 138-140 (dec.) & ------ \\
\hline $5 \mathbf{h}$ & $\mathrm{H}$ & $\mathrm{CO}_{2} \mathrm{Me}$ & $\mathrm{Br}$ & 30 & 85 & 130-132 (dec.) & ------ \\
\hline
\end{tabular}

${ }^{a}$ Isolated yields of the pure products obtained after recrystallization of the crude solid from EtOH (95.5\%). ${ }^{\text {b }}$ References 12,13 . ${ }^{\mathrm{c}}$ The product was separated by column chromatography on silica gel (n-Hexane : Ethyl acetate, 2:1).
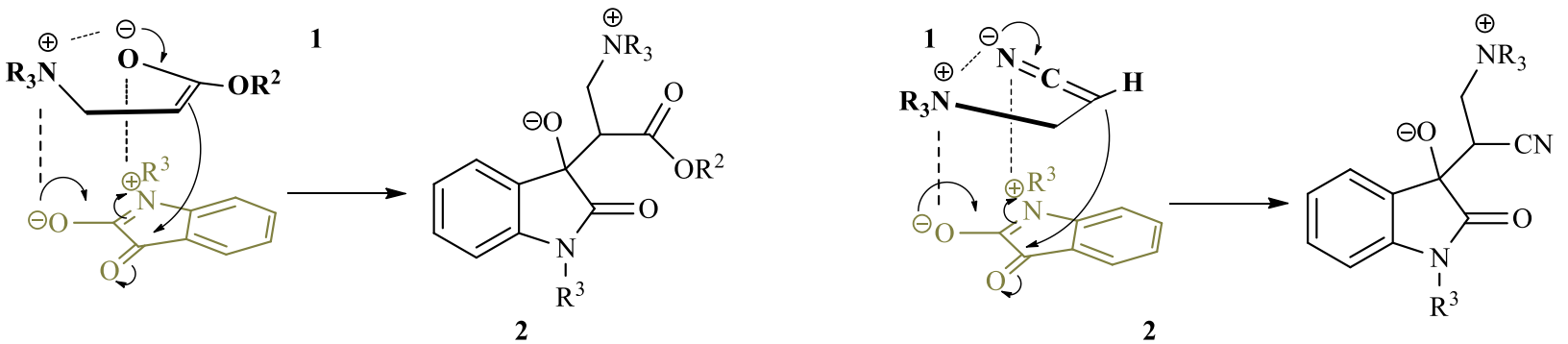

Scheme 2. Transient aggregates intervening between intermediate zwitterionic adducts $\mathbf{1}$ and $\mathbf{2}$.

Formation of these more ordered transition states intervening between the two zwitterionic adducts $\mathbf{1}$ and $\mathbf{2}$ should require a concentrated solution of reactants and conclusively is inversely dependent on temperature. On other hand, formation of this aggregate would be hindered by the presence of bulky substituents at nitrogen atom of isatin. Virtually, best results in terms of 
reaction rate and yields were obtained in solvent-free conditions at $0{ }^{\circ} \mathrm{C}$ by using excess acrylic ester or acrylonitrile. In addition, as expected, $N$-benzylisatin and $N$-methylisatin gave lower yields during a comparable time under this condition. Another reason for the lower reactivity of these $N$-substituted isatins may be due to the absence of $\mathrm{N}-\mathrm{H}$ function in their structures, which may be responsible for carrying proton shift in the last formed zwitterions 2 prior to elimination of the tert-amine catalyst. Attempts to extend the method for synthesis of previously unreported $\mathrm{MBH}$ derivatives of electron-rich isatins such as 5-methylisatin and 5-methoxyisatin remained unsuccessful.

All the products, except the one derived from $N$-benzylisatin $\mathbf{5 b}$, were simply separated and purified by recrystallization. It is important to point out that no byproduct was observed in the reaction medium. The known products have physical data consistent with those reported in literatures as well as the authentic samples prepared from previously reported methods. The new products were characterized by their IR, ${ }^{1} \mathrm{H} \mathrm{NMR}$, and ${ }^{13} \mathrm{C} \mathrm{NMR}$ spectral data as well as elemental analysis. The IR spectrum of 5f, for example, reveals well defined molecular vibrations including the characteristic bands relating to $\mathrm{O}-\mathrm{H}$ and $\mathrm{N}-\mathrm{H}$ stretching at 3420 and $3210 \mathrm{~cm}^{-1}$, respectively. The $\mathrm{C}=\mathrm{O}$ stretching vibration of ester and amide groups were observed as distinct and separate bands at 1730 and $1710 \mathrm{~cm}^{-1}$. The strictly first order ${ }^{1} \mathrm{H}$ NMR spectrum of $\mathbf{5 f}$ displayed the down-field resonance of N-H proton at $\delta 10.37$. In aromatic region the 6-H was readily perceived at $\delta 7.04$ as a doublet of triplet with ${ }^{3} J$ and ${ }^{4} J$ values of 8.5 and $2.6 \mathrm{~Hz}$ due to fairly strong couplings with ortho $(5-\mathrm{F}$ and $7-\mathrm{H})$ and meta $(4-\mathrm{H})$ nuclei. Accordingly, the peak at $\delta 6.82$ with doublet of doublet appearance was distinguished as the signal arising from $4-\mathrm{H}$ resonance, since it has a ${ }^{4} J$ of $2.6 \mathrm{~Hz}$ corresponding to the meta coupling with 6-H. Consequently, the peak appeared as $d d$ at $\delta 6.80$ was assigned to 7- $\mathrm{H}$. There are also two doublets at $\delta 6.48$ and 6.42 that were recognized as coming from vinylic protons having mutual geminal coupling of ${ }^{2} J=1.2 \mathrm{~Hz}$. Aliphatic protons of the esteric group along with the $\mathrm{OH}$ proton also appeared at appropriate chemical shifts. The ${ }^{13} \mathrm{C}$ NMR spectrum of $\mathbf{5 f}-\mathbf{h}$ showed the expected signals in agreement with structure of products.

\section{Conclusions}

In summary, we have developed here an expedient and "green" method for the synthesis of Morita-Baylis-Hillman adducts of isatin derivatives through an approach to the intrinsic higher rate of reaction between isatins and acrylic esters or acrylonitrile in solvent-free and cold conditions. The $1 H$-isatin derivatives, unlike aldehydes, have experienced more acceleration during $\mathrm{MBH}$ reaction with acrylonitrile at $0{ }^{\circ} \mathrm{C}$ and solvent-free conditions. An extended mechanism was proposed to explain the effect of low temperature on progress of $\mathrm{MBH}$ reaction of isatin derivatives. The prominent benefits of the present method are solvent-free conditions, simple experimental procedure, high yields, short reaction times, and easy workup procedure. 


\section{Experimental Section}

General. All of the solvents and reagents were purchased from Fluka or Merck chemical companies. Melting points were measured on an Electrothermal apparatus. IR spectra were obtained in $\mathrm{KBr}$ discs on a Shimadzu IR-470 spectrometer. ${ }^{1} \mathrm{H}$ and ${ }^{13} \mathrm{C}$ NMR spectra were measured with Brucker DRX-500 spectrometer. Chemical shifts of ${ }^{1} \mathrm{H}$ and ${ }^{13} \mathrm{C}$ NMR spectra were expressed in ppm downfield from tetramethylsilane. Elemental analyses for $\mathrm{C}, \mathrm{H}$ and $\mathrm{N}$ were performed using a Foss Heraus CHN-O-rapid analyzer.

\section{General procedure for preparation of compounds (5a-h)}

A mixture of an isatin derivative $(1 \mathrm{mmol})$, activated olefin $(2 \mathrm{mmol})$, and DABCO (1 mmol, $0.11 \mathrm{~g}$ ) was stirred at $0{ }^{\circ} \mathrm{C}$ for appropriate time (Table 1). At the end of reaction (as monitored by TLC using a 2:1 solution of $n$-hexane: EtOAc as eluent), the residue was washed with cold EtOAc $(2 \times 15 \mathrm{~mL})$. The remained crude product was recrystallized from ethanol $(95.5 \%)$. The EtOAc used for washing the crude products was kept in refrigerator to separate DABCO as crystals. Details of previously unreported compounds are as follows.

Ethyl 2-(5-fluoro-3-hydroxy-2-oxoindolin-3-yl)acrylate (5f). Lavender crystals $(0.21 \mathrm{~g})$ 80\%, M.p.: $148-150^{\circ} \mathrm{C}$ (decomp.). IR: $v_{\max } 3420$ (O-H str.), 3210 (N-H str.), 2985, 1730, 1710, 1490, 1320, 1180, 1063, $780 \mathrm{~cm}^{-1} .{ }^{1} \mathrm{H}$ NMR (500 MHz, DMSO-d $): \delta 1.03\left(\mathrm{t},{ }^{3} J_{\mathrm{HH}} 7.1 \mathrm{~Hz}, 3 H\right), 3.98-$ $3.90\left(\mathrm{~m}, 2 \mathrm{H}, \mathrm{O}-\mathrm{CH}_{2}\right), 3.40$ (br s, $\left.1 \mathrm{H}, \mathrm{OH}\right), 6.42(\mathrm{~d}, J 1.2 \mathrm{~Hz}, 1 \mathrm{H}$, vinylic), $6.48(\mathrm{~d}, J 1.2 \mathrm{~Hz}, 1 \mathrm{H}$, vinylic), 6.80 (dd, $J 8.5$ and $4.3 \mathrm{~Hz}, 7-\mathrm{H}$ ), 6.82 (dd, $J 8.5$ and $2.6 \mathrm{~Hz}, 4-\mathrm{H}$ ), 7.04 (dt, $J 8.5$ and 2.6 $\mathrm{Hz}, 6-\mathrm{H}), 10.37$ (s, N-H). ${ }^{13} \mathrm{C}$ NMR (125.8 MHz, DMSO-d 6$)$ : $\delta 14.4\left(\mathrm{CH}_{3}\right), 61.3\left(\mathrm{CH}_{2}\right), 76.3(\mathrm{C}-$ $\mathrm{OH}), 111.1\left(\mathrm{~d},{ }^{3} J_{\mathrm{C}-\mathrm{F}} 7.6 \mathrm{~Hz}, \mathrm{CH}\right), 112.0\left(\mathrm{~d},{ }^{2} J_{\mathrm{C}-\mathrm{F}} 24.5 \mathrm{~Hz}, \mathrm{CH}\right), 116.2\left(\mathrm{~d},{ }^{2} J_{\mathrm{C}-\mathrm{F}} 23 \mathrm{~Hz}, \mathrm{CH}\right), 128.4$ $\left(=\mathrm{CH}_{2}\right), 134.4\left(\mathrm{~d},{ }^{3} J_{\mathrm{C}-\mathrm{F}} 7.7 \mathrm{~Hz}, \mathrm{C}\right), 140.2(\mathrm{C}), 140.4(\mathrm{C}), 158.6\left(\mathrm{~d},{ }^{1} J_{\mathrm{C}-\mathrm{F}} 236.8 \mathrm{~Hz}, \mathrm{C}\right), 164.8$ $(\mathrm{C}=\mathrm{O}), 177.84(\mathrm{C}=\mathrm{O})$. Anal. Calcd. for $\mathrm{C}_{13} \mathrm{H}_{12} \mathrm{FNO}_{4} ; \mathrm{C} 58.87, \mathrm{H}$ 4.56, N 5.28; found $\mathrm{C} 58.94, \mathrm{H}$ 4.69, N 5.03.

Methyl 2-(5-fluoro-3-hydroxy-2-oxoindolin-3-yl)acrylate (5g). Lavender crystals (0.21 g) 83\%, M.p.: 138- $140^{\circ} \mathrm{C}$ (decomp.). IR: $v_{\max } 3410$ (O-H str.), 3215 (N-H str.), 1735, 1717, 1495, 1325, 1080, $780 \mathrm{~cm}^{-1} .{ }^{1} \mathrm{H}$ NMR (500 MHz, DMSO-d ${ }_{6}$ ): $\delta 3.40$ (br s, $\left.1 \mathrm{H}\right), 3.53\left(\mathrm{~s}, 3 \mathrm{H}, \mathrm{O}_{-} \mathrm{CH}_{3}\right.$ ), 6.45 (s, 1H, vinylic), 6.49 (s, 1H, vinylic), 6.79-6.83 (m, 2H, 7- $\mathrm{H}$ and 4- $\mathrm{H}), 7.01-7.03(\mathrm{~m}, 1 \mathrm{H}, 6-$ $\mathrm{H}), 10.37(\mathrm{~s}, \mathrm{~N}-\mathrm{H}) .{ }^{13} \mathrm{C}$ NMR $\left(62.9 \mathrm{MHz}, \mathrm{DMSO}-\mathrm{d}_{6}\right): \delta 52.2\left(\mathrm{CH}_{3}\right), 75.9\left({ }^{13} \mathrm{C}-\mathrm{OH}\right), 110.8\left(\mathrm{~d},{ }^{3} J_{\mathrm{C}-}\right.$ F $6.9 \mathrm{~Hz}, \mathrm{CH}), 111.5\left(\mathrm{~d},{ }^{2} J_{\mathrm{C}-\mathrm{F}} 23.9 \mathrm{~Hz}, \mathrm{CH}\right), 116.0\left(\mathrm{~d},{ }^{2} J_{\mathrm{C}-\mathrm{F}} 23.9 \mathrm{~Hz}, \mathrm{CH}\right), 128.2\left(\mathrm{CH}_{2}\right), 133.8(\mathrm{~d}$, $\left.{ }^{3} J_{\mathrm{C}-\mathrm{F}} 14.5 \mathrm{~Hz}, \mathrm{C}\right), 139.7$ (C), $139.8(\mathrm{C}), 158.1$ (d, $\left.{ }^{1} J_{\mathrm{C}-\mathrm{F}} 215 \mathrm{~Hz}, \mathrm{C}\right), 164.9(\mathrm{C}=\mathrm{O}), 177.5(\mathrm{C}=\mathrm{O})$. Anal. Calcd. for $\mathrm{C}_{12} \mathrm{H}_{10} \mathrm{FNO}_{4}$; C 57.37, H 4.01, N 5.58; found C 57.42, H 4.11, N, 5.43.

Methyl 2-(5-bromo-3-hydroxy-2-oxoindolin-3-yl)acrylate (5h). Milky crystals $(0.26 \mathrm{~g})$ 85\%, M.p.: $130-132^{\circ} \mathrm{C}$ (decomp.). IR: $v_{\max } 3430$ (O-H str.), 3200 (N-H str.), 2940, 1736, 1718, 1185, $775 \mathrm{~cm}^{-1} .{ }^{1} \mathrm{H}$ NMR (500 MHz, DMSO-d $): \delta 3.54\left(\mathrm{~s}, 3 \mathrm{H}, \mathrm{CH}_{3}\right), 4.33$ (br s, $\left.1 \mathrm{H}, \mathrm{OH}\right), 6.46(\mathrm{~s}, 1 \mathrm{H}$, vinylic), 6.51 (s, $1 \mathrm{H}$, vinylic), $6.80\left(\mathrm{~d},{ }^{3} J_{\mathrm{HH}} 7.5 \mathrm{~Hz}, 1 \mathrm{H}, 7-\mathrm{H}\right), 7.08(\mathrm{~s}, 1 \mathrm{H}, 4-\mathrm{H}), 7.38\left(\mathrm{~d},{ }^{3} J_{\mathrm{HH}} 7.5\right.$ $\mathrm{Hz}, 1 \mathrm{H}, 6-\mathrm{H}) .{ }^{13} \mathrm{C}$ NMR $\left(125.8 \mathrm{MHz}, \mathrm{DMSO}-\mathrm{d}_{6}\right): \delta 52.6\left(\mathrm{CH}_{3}\right), 76.0(\mathrm{C}), 112.5(\mathrm{CH}), 113.7(\mathrm{C})$, $126.9\left(\mathrm{CH}_{2}\right), 128.7(\mathrm{CH}), 132.8(\mathrm{CH}), 135.0(\mathrm{C}), 140.0(\mathrm{C}), 143.4(\mathrm{C}), 165.3(\mathrm{C}=\mathrm{O}), 177.4$ $(\mathrm{C}=\mathrm{O})$. Anal. Calcd. for $\mathrm{C}_{12} \mathrm{H}_{10} \mathrm{BrNO}_{4} ; \mathrm{C} 46.18, \mathrm{H} 3.23, \mathrm{~N} 4.49$; found C 46.22, H 3.31, N 4.38. 


\section{Acknowledgements}

We gratefully acknowledge the financial support from the Research Council of University of Guilan

\section{References}

1. Schreiber, S. L. Science 2000, 287, 1964.

2. Burke, M. D; Berger, E. M.; Schreiber, S. L. Science 2003, 302, 613.

3. Basavaiah, D.; Rao, A. J.; Satyanarayana, T. Chem. Rev. 2003, 103, 811.

4. Singh, V.; Batra, S. Tetrahedron 2008, 64, 4511.

5. Basavaiah, D.;.Reddy, B. S.; Badsara, S. S. Chem. Rev. 2010, 110, 5447.

6. Shanmugam, P.; Rajasingh, P. Tetrahedron 2004, 60, 9283.

7. Coelho, F.; P. Almeida, W.; Veronese, D.; Mateus, C.; C. Silva Lopes, E.; C. Rossi, R.; P. C. Silveira, G.; H. Pavam, C. Tetrahedron 2002, 58, 7437.

8. Shi, M.; Jiang, J-K.; Cui, S-C. Tetrahedron 2001, 57, 7343.

9. Oishi, T.; Oguri, H.; and Hirama, M. Tetrahedron: Asymmetry 1995, 6, 1241.

10. Song, Y.; Ke, H.; Wang, N.; Wang, L.; Zou, G. Tetrahedron 2009, 65, 9086.

11. de Souza, R. O. M. A.; Vasconcellos, M. L. A. A. Catal. Commun. 2004, 5, 21.

12. Garden, S. J.; Skakle, J. M. S. Tetrahedron Lett. 2002, 43, 1969.

13. Chung, Y. N.; Im, Y. J.; Kim, J. N. Bull. Korean. Chem. Soc. 2002, 11, 1651.

14. Basavaiah, D. and Rao, A. J. Tetrahedron Lett. 2003, 44, 4365.

15. Yang, K. S.; Lee, W. D.; Pan, J. F. and Chen, K. J. Org. Chem. 2003, 68, 915.

16. (a) Shanmugam, P.; Vaithiyanathan, V.; Viswambharan, B. Tetrahedron 2006, 62, 4342. (b) Shanmugam, P.; Viswambharan, B.; Selvakumar, K.; Madhavan, S. Tetrahedron 2008, 49, 2611. (c) Shanmugam, P.; Viswambharan, B. and Madhavan, S. Org. Lett. 2007, 9, 4095.

17. (a) Gazit, A.; Osherov, N.; Posner, I.; Yaish, P.; Poradosu, E.; Gilon, C.; Levitzki, A. J. Med. Chem. 1991, 34, 1896.(b) A. Klumpp, D.; Yeung, K. Y.; Prakash, G. K. S.; A. Olah, G. J. Org. Chem. 1998, 63, 4481. (c) Rahrman, A. H. A.; Keshk, E. M.; Hanna, M. A. Bioorg. Med. Chem. 2004, 12, 2483

18. Jimenez, J. I.; Huber, U.; Moore, R. E.; Patterson, G. M. L. J. Nat. prod. 1999, 62, 569.

19. Kawasaki, T. Nagaoka, M.; Satoh, T.; Okamoto, A.; Ukon, R.; Ogawa, A. Tetrahedron 2004, 60, 3493.

20. Fre'chard, A.; Fabre, N.; Pe'an, C.; Montaut, S.; Fauvel, M-T.; Rollin, P.; Fouraste', I. Tetrahedron Lett. 2001, 42, 9015.

21. Rafel, S.; W. Leahy, J. J. Org. Chem. 1997, 62, 1521. 